\title{
Bioremediation and recovery of metals from mine waters by $\mathrm{Mn}$ - oxidizing micro-eukaryotes
}

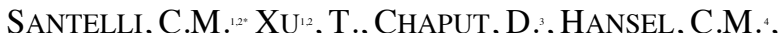
AND TRIPP, $R$.

'Earth and Environmental Sciences, University of Minnesota,

Minneapolis, MN, USA, santelli@umn.edu

BioTechnology Institue, University of Minnesota, St. Paul, MN, USA, txu@umn.edu

${ }^{3}$ Biosciences, University of Exeter, Exter, UK

${ }^{4}$ Marine Chemistry and Geochemistry, Woods Hole

Oceanographic Institution, Woods Hole, MA, USA

Manganese $(\mathrm{Mn})$ oxides are ubiquitous minerals that control the fate and transport of heavy metals and nutrients through co-precipitation, sorption, and redox processes. In natural environments, the formation of $\mathrm{Mn}(\mathrm{III} / \mathrm{IV})$ oxide minerals from $\mathrm{Mn}(\mathrm{II})_{\text {aq }}$ oxidation is largely promoted by microbiological (including micro-eukaryotic) activity. Our work demonstrates that a diversity of fungi and algae thrive in Mn-rich mining and industrial wastewaters and contribute greatly to Mn oxide formation. The biogenic Mn oxides are highly reactive and can serve as natural sponges to sequester many heavy metal co-contaminants. The effective capture of these metals represents great potential for development and improvement of current bioremediation strategies, with the downstream recovery of high value metals presenting an opportunity for greater economic growth.

Mining and industrial wastewaters vary widely in their composition, so laboratory experiments were conducted over a range of conditions to understand the co-removal capacity of multiple metals (e.g., $\mathrm{Mn}$, cobalt $(\mathrm{Co})$, copper $(\mathrm{Cu})$, and nickel (Ni)). For one set of experiments, Mn-oxidizing fungi isolated from a former iron ore mine were used to explore metal co-removal processes, comparing mechanisms of coprecipitation versus metal sorption by mycogenic $\mathrm{Mn}$ oxides under high salt conditions observed in the mine (and common in many industrial waste streams). $\mathrm{Co}, \mathrm{Cu}, \mathrm{Ni}$, and Mn uptake by biomass and Mn oxides were tracked with wet chemistry techniques to determine the rate and effeciency of metal removal from the growth media. X-ray absorption fine structure (XAFS) spectroscopy was used to determine redox sensitive metal oxidation states, target metal binding behaviors and structure transformation. Additional experiments using bench-scale bioreactors examined the effect of various growth supplements on metal capture using a natural community obtained from field bioreactors. Results from this study will bring new insight into bioremediation and metal recovery strategies towards various environments. 